4 as a hospital dentist and a GDP. He has been the primary contact for family history research enquiries from the public, helping to make the BDA's Museum archive accessible to all and generating much-needed income. As an excellent communicator and speaker, he has delivered tours of the Museum to adults, children, foundation dentists and dental practice visitors, always garnering excellent feedback. He has represented the Museum at the BDA's annual conferences, at the All-Party Parliamentary Group for Dentistry and Oral Health meetings, and many other events. He has taken an active role in building up the McLean Oral History Archive, interviewing dentists and dental care professionals. He has been Honorary Secretary of the Lindsay Society for the History of Dentistry since 2009. Brian's dedicated work and wonderful sense of humour have been invaluable in helping the BDA's Museum continue its popularity and success.

\section{Certificate of Merit for Services to the} Profession

Shareena Ilyas qualified in 1998 and is currently a GDP working as an associate in a mixed NHS practice in London. She was elected to the BDA's Board in April 2020, the first Asian woman to sit on our Board since its inception. She has since taken on the roles of Chair of the BDA's Education Ethics and the Dental Working Group and is co-Chair of the BDA's newly formed Equality, Inclusion and Diversity Committee. Shareena has always been active at a local level, taking part in her Branch and LDC activities and encouraging younger members to get more engaged in dental politics, as well as representing dentists at a national level. She is passionate about supporting peers and since 2018 has worked with HEE Oxford as a coach/mentor for dentists in difficulty. She is a Trustee of the charity, The Sterling Dental Group, and has raised almost $£ 100,000$ for Great Ormond Street, the India Association (Bobby's Walk) and Ataxia charities.

\section{Roll of Distinction}

Ian Morley's long career at the BDA began in 1992 as a Legal Advisor. He later took on the role as the BDA's first HR Manager in 2001, and devised many of the BDA's policies and procedures, enabling the organisation to ensure transparent, equitable and consultative processes. Ian became Head of HR and Governance in 2004, helping to revise the BDA's Articles of Association in 2012-2013, which saw the representative structure of the BDA change fundamentally - moving away from an Executive Board and Representative Body format to the BDA's current Principal Executive Committee, various Standing Committees, and Country and UK Council structure. Ian then took on the role of Head of Corporate Governance from 2018 until 2020. Ian has been a fundamental part of the fabric of the BDA over such a long period of time, providing much wise counsel for colleagues and elected representatives alike.

\section{Awards ceremonies for 2021}

Unfortunately, because of the pandemic, there has been a delay in the presentation of the 2019 Awards to recipients due to the ongoing restrictions. The BDA hopes to be able to offer an Awards presentation for last year's awardees, as well as a ceremony for the 2020 recipients during 2021, and will keep members updated on developments.

\title{
FGDP marks 15 years of raising standards in implant dentistry
}

The Faculty of General Dental Practice UK (FGDP) is celebrating the fifteenth anniversary of Training standards in implant dentistry, its publication which defines the training that should be undertaken to carry out implant dentistry safely.

Training standards in implant dentistry is available from a variety of providers including the Faculty, which has trained over 700 dentists through its respected postgraduate diploma course - and this publication sets the standards which UK training courses should meet.

Available free of charge at https://www. fgdp.org.uk/guidance-standards, the document also serves as a reference point for the General Dental Council in the consideration of patient complaints against dentists who have allegedly practised implant dentistry in the UK without the necessary competence.

A review published in 2018 concluded that the development of Training standards

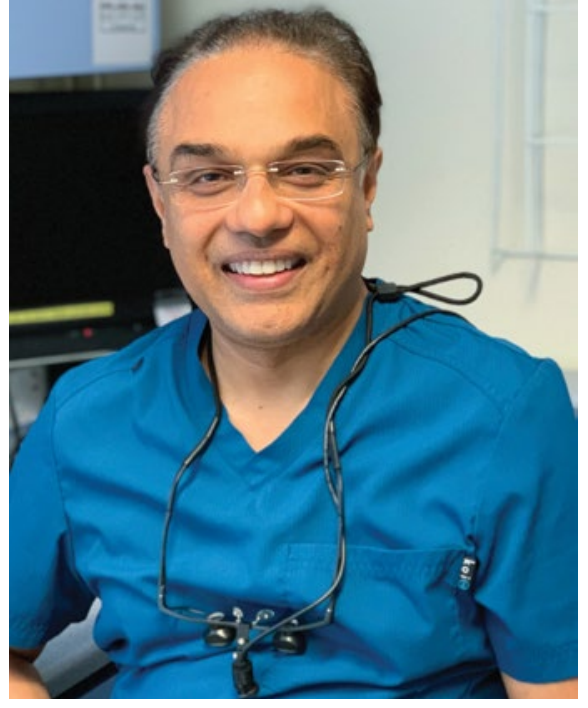

in implant dentistry had 'led to a significant improvement in the quality of postgraduate education in dental implantology in the UK. ${ }^{1}$

However, the review also concluded that 'the provision of mentoring for implant placements needs to be standardised', and the Faculty is currently working with the Association of Dental Implantology to set out more detailed mentoring requirements, which are expected to be published as an appendix to the current guidance in 2021.

Abhi Pal, Editor of Training standards in implant dentistry and Chair of the Faculty's Professional Affairs Committee (pictured), said: 'Developed to standardise and improve training in implant dentistry, Training standards in implant dentistry ultimately helps give patients the confidence they need to seek appropriate treatment. The anniversary of its publication is a moment to celebrate the high standards of training and practice which it underpins, and which dental patients in the UK have been benefiting from for the last 15 years'.

\section{Reference}

1. $\operatorname{Kim} N$ Y, Stagnell S. Postgraduate education in dental implantology in the United Kingdom: a review. Int J Implant Dent 2018; 4: 8. https://doi. org/10.1186/s40729-017-0115-1. 